\title{
Brain atrophy in chronic alcoholic patients: a quantitative pathological study
}

\author{
CLIVE HARPER, JILLIAN KRIL
}

From the Department of Neuropathology, Royal Perth Hospital, Perth, Australia

SUMMARY There are essentially no objective neuropathological data on brain atrophy in chronic alcoholic patients despite numerous neuroradiological studies which show a high incidence of shrinkage or atrophy. Therefore measurements were made of the intracranial volume (ICV) and brain volume (BV) in a necropsy study of 25 chronic alcoholic patients and 44 controls. The pericerebral space (PICS) was calculated according to the formula PICS $=\frac{\text { ICV }- \text { BV }}{\text { ICV }} \times \frac{100}{1} \%$.

The PICS will increase in patients with brain atrophy since the ICV remains constant throughout life. The mean PICS value was $8.3 \%$ in controls, $11.3 \%$ in the alcoholic group, $14.7 \%$ in alcoholics with superimposed Wernicke's encephalopathy (thiamine deficiency) and $16.2 \%$ in those alcoholics with associated liver disease. Thus there was a statistically significant loss of brain tissue in chronic alcoholic patients which appeared to be more severe in those with associated nutritional vitamin deficiencies or alcoholic liver disease.

Brain shrinkage in chronic alcoholic patients as demonstrated by pneumoencephalographic studies ${ }^{1}$ and computed tomography ${ }^{2-4}$ is now a well accepted fact. That some of this shrinkage is reversible following prolonged abstinence from alcohol is also well documented. ${ }^{56}$ Abnormalities of brain function including specific cognitive deficits ${ }^{7}$ and a more generalised global dementia may well relate directly to chronic alcohol abuse. ${ }^{8}$ Pathological data on the cerebral cortex of these cases are somewhat sparse and continual pleas have been made by many authors in the last decade for more detailed neuropathological studies of the brains of alcoholic patients. ${ }^{8-10}$ Courville ${ }^{11}$ commented on widespread cortical atrophy with preferential involvement of the frontal lobes in chronic alcoholics. Victor, Adams and Collins ${ }^{12}$ noted cerebral cortical atrophy in $27 \%$ of their cases of Wernicke's encephalopathy. Although most cases of Wernicke's encephalopathy are associated with chronic alcoholism,,$^{13}$ pathological studies of these cases have been directed at the more traditional periventricular lesions. Studies of

Address for reprint requests: Dr CG Harper, Department of Neuropathology, Royal Perth Hospital, Box X2213, GPO Perth, Western Australia 6001.

Received 11 May 1984 and in revised form 21 July 1984. Accepted 29 July 1984 the cerebral cortex have not extended beyond the subjective assessment of the presence or absence of cerebral atrophy macroscopically and comments such as "patchy cortical neuronal loss" at the microscopic level.1113 An additional complication in studying cases of Wernicke's encephalopathy is that these patients may have a mixture of pathological entities. They have a proven nutritional vitamin deficiency (thiamine), often chronic liver disease (fatty liver or cirrhosis) as well as a long history of ethanol abuse. Fortunately, those patients with hepatic encephalopathy and/or Wernicke's encephalopathy can be identified at necropsy by detailed microscopic neuropathological studies.

There is some indirect objective pathological evidence that brain atrophy occurs in chronic alcoholic patients. It has been shown that the mean brain weight of chronic alcoholic males is significantly less than that of a control group. ${ }^{14}$ is However, the interpretation of any brain weight study is difficult because of the wide range of normal values. ${ }^{14}$ The results would be far more meaningful if a reduction in the brain weight and volume could be documented in relation to the time span of alcohol abuse. This can be achieved by measuring both the brain volume (BV) and the intracranial volume (ICV). During childhood the growth of the brain determines the growth and expansion of the skull ${ }^{16}$ and the ICV remains unchanged during life. ${ }^{17}$ In the 


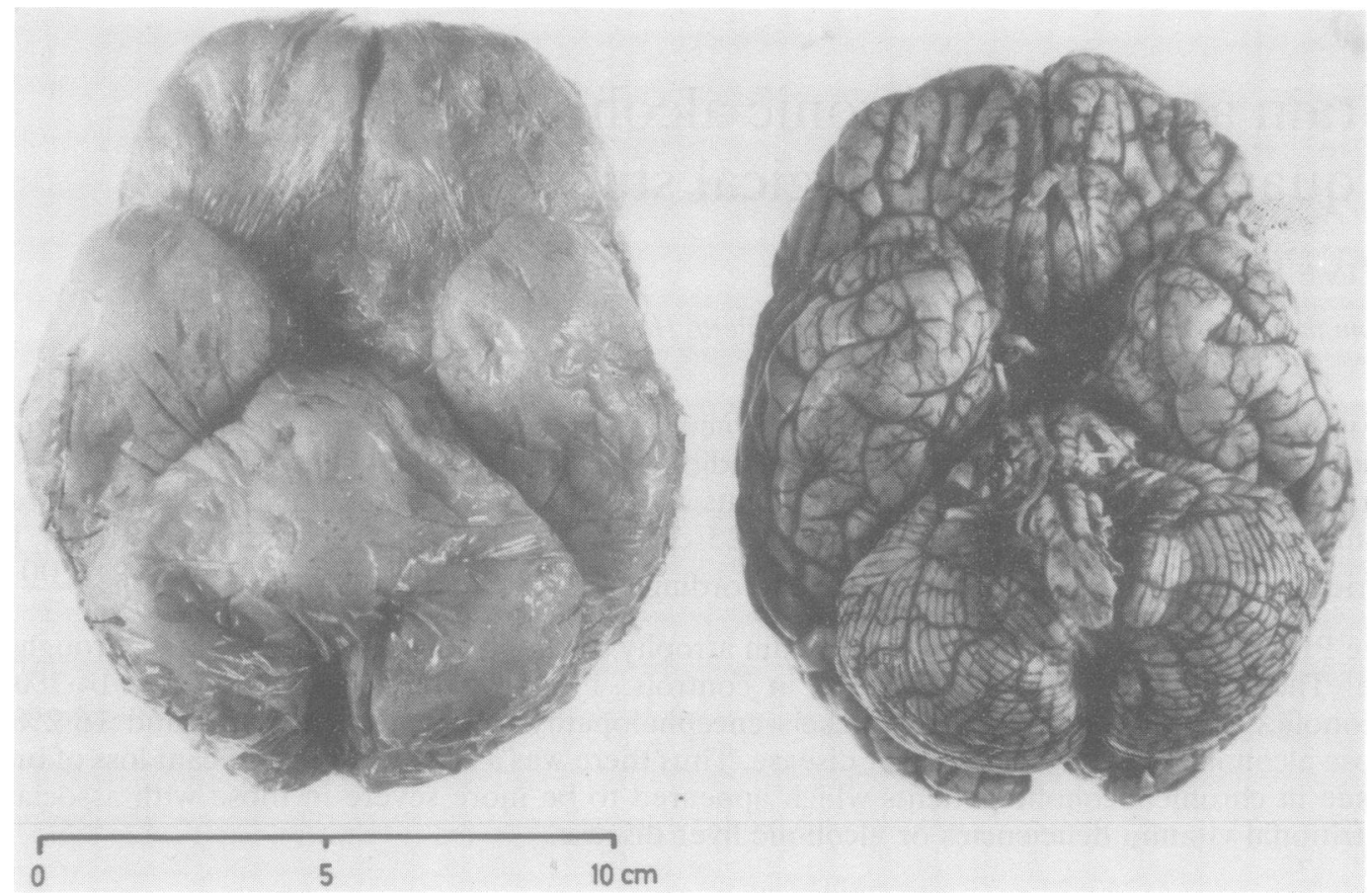

Fig 1 The polyurethane foam cast (left) gives an accurate replication of the intracranial vault and allows the intracranial volume to be calculated and compared with the brain (right) volume.

normal population there is a close correlation between BV and ICV. ${ }^{17} 18$ There are very few large studies of these parameters in either normal populations or pathological states. This probably relates to the logistic and mechanical difficulties of obtaining these measurements during routine necropsies. The authors have recently described a new technique for measuring the ICV by making polyurethane foam casts (fig 1) of the intracranial cavity. ${ }^{19}$

The most useful parameter which can be derived from the ICV and BV measurements has been termed the pericerebral space (PICS). ${ }^{17}$

$$
\mathrm{PICS}=\frac{\mathrm{ICV}-\mathrm{BV}}{\mathrm{ICV}} \times \frac{100}{1} \%
$$

In effect the PICS is a measure of the volume of cerebrospinal fluid (CSF) covering the surface of the brain and lying within the various cisterns (fig 2). This does not include ventricular or spinal CSF. As the brain becomes atrophic or shrinks the PICS value will increase. ${ }^{1719}$ This study compares the PICS values of alcoholics and controls.

\section{Materials and methods}

One hundred and fifteen cases were studied in conjunction with the Forensic Pathologist of the Perth City Coroner's
Department. One of the authors (JK) attended the necropsies and carried out the procedures as described herein.

Cases for the study were selected on the basis of a nega-e tive neurological history apart from alcohol related disor-? ders such as Wernicke's encephalopathy or epilepsy (a significant proportion of alcoholics are also epileptic ${ }^{20}$ ). Cases in which brain swelling was likely to have occurred (for example head injuries) and cases which had macroscopic evidence of swelling were excluded. Assessment of "alcoholic" or "control" status was based on clinical notes available from the major teaching hospitals in Perth as a result of previous admissions. These were available in $70 \%$ of cases. The next of kin were interviewed when possible to assess the duration and quantity of alcohol consumption and the person's nutritional status. All cases were subject to a complete necropsy with microscopic examination of tissues. Relevant findings such as fatty liver or cirrhosis were helpful indicators of the extent of alcohol abuse. Reports concerning the circumstances surrounding the death were also helpful. In many cases liver function tests were available and in six cases, CT scans had been done during previous hospital admissions (fig 3).

After consideration of all the available data, 69 of the 115 cases were selected for this study. There were 25 alcoholic patients and 44 controls.

The necropsies were carried out in a standard fashion as was removal of the brains. The dura mater was left attached to the skull. The brain was dried and weighed immediately on a standard balance which has a nominal error of 


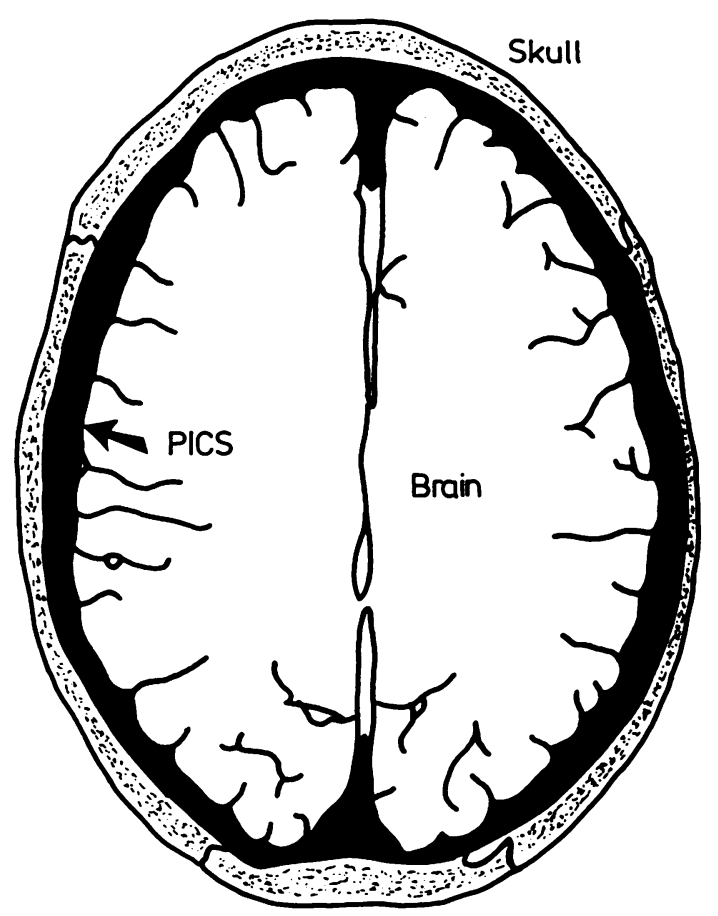

Fig 2 Schematic representation of the pericerebral space (PICS) which is calculated according to the equation:

$P I C S=\frac{\text { Intracranial volume }- \text { fresh brain volume } \times 100 \%}{\text { Intracranial volume }}$ and represents the "space" between the skull and the brain.

\pm 5 grams. The fresh brain volume was determined by the fluid displacement method (Archimedes' principle) using $0 \cdot 15 \mathrm{~N}$ saline as the immersion fluid. A polyurethane foam cast (fig 1) was then made of the intracranial cavity according to the method described recently by the authors. ${ }^{19}$ The volume of the cast and hence the intracranial volume was determined by the fluid displacement technique. Anatomical parameters including head circumference and maximum internal skull length and width were measured. The brains were fixed in $10 \%$ formol saline for two weeks. The brains were then embedded in a $3 \%$ agarose block and cut into $3 \mathrm{~mm}$ coronal slices using an electric meat slicer. This allowed detailed macroscopic examination of the cases. (This material will be the subject of further quantitative morphometric analyses). Sections were taken for histological examination to identify those patients with Wernicke's encephalopathy and/or hepatic encephalopathy and to exclude diagnoses such as Alzheimer's disease which could cause cerebral cortical atrophy. PICS values were determined according to the equation

PICS $=\frac{\mathrm{ICV}-\mathrm{BV}}{\mathrm{ICV}} \times \frac{100 \%}{1}$. Statistical analyses were

carried out using the Student $t$ test when variances of the two groups were equal. The Cochran ${ }^{21}$ and Behrens ${ }^{21}$ mod- ifications of the $t$ test were applied when the variances were unequal. The $p$ values were almost identical for both of these tests. Because we were only interested in PICS values which exceeded the upper limit of the normal range, the one tailed $\mathrm{p}$ value was determined.

\section{Results}

Of the 69 selected cases there were 44 controls and 25 alcoholics, ten of whom had chronic Wernicke's encephalopathy (microscopic diagnosis). The results of this latter group were analysed separately (alcoholic/Wernicke's encephalopathy group). The clinical details for each of the alcoholic groups of patients are summarised in table 1. As is generally the case in any study of an alcoholic population, the males outnumbered the females $(5: 1)$. The mean age of the control group was 58 years which was the same as the alcoholic/Wernicke's encephalopathy group. However, the mean age of the alcoholic group was 50 years. Six of the alcoholic cases were epileptic, but none had histologic evidence of hypoxic brain damage.

There was a poor correlation between the intracranial volume (ICV) and body height, weight or skull width. There was some correlation between the ICV and skull length and a less significant correlation with head circumference. However, these measurements are of little practical value in the accurate determination of ICV.
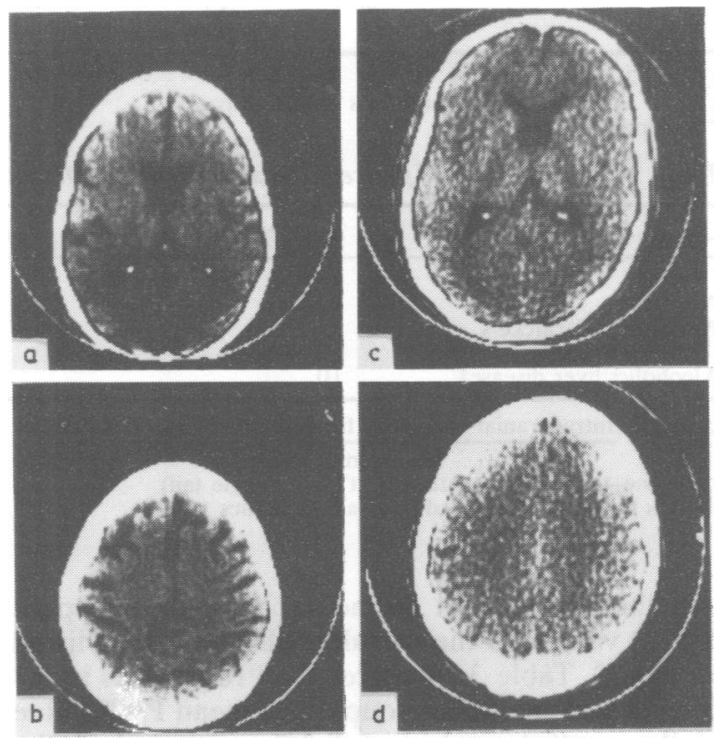

Fig 3 (a, b) CT scan of a 52-year-old female alcoholic (case 29) with Wernicke's encephalopathy and a PICS value of $13.7 \%$. Note widening of cortical sulci and ventricular enlargement and compare with CT scan of control case. (c, d) a 54-year-old male (case 38) with a PICS value of $8.3 \%$. 
Table 1 Clinical details of 69 cases studied

\begin{tabular}{lllllc}
\hline Group & $\begin{array}{l}\text { Number } \\
\text { of cases }\end{array}$ & $\begin{array}{l}\text { Mean } \\
\text { Age }(y r)\end{array}$ & \multicolumn{2}{l}{ Sex } & Epilepsy \\
\cline { 3 - 6 } & & & Male & Female & \\
\hline Controls & 44 & 58 & 37 & 7 & 0 \\
$\begin{array}{l}\text { Alcoholics } \\
\text { Alcoholics/Wernicke's }\end{array}$ & 15 & 50 & 14 & 1 & 5 \\
\hline
\end{tabular}

Table 2 Pathological details of 25 alcoholics

\begin{tabular}{|c|c|c|c|c|c|c|c|}
\hline $\begin{array}{l}\text { Case } \\
\text { number }\end{array}$ & $\begin{array}{l}\text { Age } \\
(y r)\end{array}$ & Sex & $\begin{array}{l}\text { Liver } \\
\text { disease }\end{array}$ & $\begin{array}{l}\text { Cortical } \\
\text { atrophy }\end{array}$ & $\begin{array}{l}\text { Ventricular } \\
\text { dilation }\end{array}$ & $\begin{array}{l}\text { Cerebellar } \\
\text { atrophy }\end{array}$ & PICS \\
\hline \multicolumn{8}{|l|}{ Group 2} \\
\hline 36 & 50 & $\mathbf{M}$ & Fatty & - & - & + & $14.2 \%$ \\
\hline 37 & 54 & $\mathbf{M}$ & $\mathrm{Nil}$ & + & - & + & $18.3 \%$ \\
\hline 39 & 73 & $\mathbf{M}$ & Nil & + & + & - & $17 \cdot 0 \%$ \\
\hline 41 & 73 & $\mathbf{M}$ & Cirrhosis & - & + & - & $16.4 \%$ \\
\hline 52 & 58 & $\mathbf{M}$ & Nil & - & - & - & $3.2 \%$ \\
\hline $55^{*}$ & 27 & $\mathbf{M}$ & Nil & - & - & - & $9.0 \%$ \\
\hline $65^{*}$ & 31 & $\mathbf{M}$ & $\mathrm{Nil}$ & - & - & - & $12.8 \%$ \\
\hline 69 & 30 & $\mathbf{M}$ & Nil & - & - & - & $2.5 \%$ \\
\hline $71^{*}$ & 48 & $\mathbf{M}$ & Nil & - & + & - & $7.4 \%$ \\
\hline 82 & 24 & $\mathbf{M}$ & Nil & - & - & - & $6.2 \%$ \\
\hline 83 & 68 & $\mathbf{M}$ & Nil & - & - & - & $11 \cdot 2 \%$ \\
\hline $84^{*}$ & 53 & $\mathbf{M}$ & Nil & - & - & - & $8.3 \%$ \\
\hline $90^{*}$ & 34 & $\mathbf{F}$ & Fatty & - & - & - & $11.0 \%$ \\
\hline 98 & 72 & $\mathbf{M}$ & Nil & - & + & + & $19.3 \%$ \\
\hline 117 & 55 & $\mathbf{M}$ & Fatty & - & - & - & $11.9 \%$ \\
\hline \multicolumn{8}{|l|}{ Group 3} \\
\hline 15 & 42 & $\mathbf{M}$ & Fatty & - & - & - & $15.7 \%$ \\
\hline $29^{*}$ & 52 & $\mathbf{F}$ & Fatty & - & - & + & $13.7 \%$ \\
\hline 56 & 57 & $\mathbf{M}$ & Fatty & + & + & - & $19.5 \%$ \\
\hline 67 & 58 & $\mathbf{M}$ & Nil & + & - & - & $12 \cdot 1 \%$ \\
\hline 78 & 57 & $\mathbf{F}$ & Cirrhosis & + & + & + & $13.0 \%$ \\
\hline 95 & 55 & $\mathbf{M}$ & Nil & - & - & + & $11.6 \%$ \\
\hline 111 & 72 & $\mathbf{M}$ & Fatty & + & + & + & $23.2 \%$ \\
\hline 113 & $5 \overline{7}$ & $\mathbf{F}$ & Fatty & + & + & + & $23.0 \%$ \\
\hline 118 & 71 & $\mathbf{M}$ & Nil & + & - & - & $5.1 \%$ \\
\hline 119 & 62 & $\mathbf{M}$ & Nil & - & + & + & $9.9 \%$ \\
\hline
\end{tabular}

Group 2 = Alcoholics

Group 3 = Alcoholics/Wernicke's encephalopathy

Epileptic

Table 3 Comparison of pericerebral space (PICS)* in control and alcoholic groups

\begin{tabular}{llcll}
\hline Group & Number of Cases & Means PICS $^{*}$ & Standard Deviation & $p$ Value $\dagger$ \\
\hline Controls & 44 & $8.3 \%$ & $\pm 3.3 \%$ & - \\
Alcoholics & 15 & $11.3 \%$ & $\pm 5.2 \%$ & $\mathrm{p}<0.02$ \\
Alcoholics/Wernicke's & 10 & $14.7 \%$ & $\pm 5.8 \%$ & $\mathrm{p}<0.006$ \\
$\quad \begin{array}{l}\text { encephalopathy } \\
\text { Alcoholics/liver disease } \neq\end{array}$ & 10 & $16.2 \%$ & $\pm 4.4 \%$ & $\mathrm{p}<0.001$ \\
\hline
\end{tabular}

*PICS $=$ Intrancranial volume - fresh brain volume $\times 100 \%$

$$
\text { Intracranial volume }
$$

†p Value-according to student " $t$ " test (single tail)

$\ddagger$ this subgroup is derived from all alcoholics

Pathologic details including pericerebral space (PICS) values for the two alcoholic groups are listed in table 2. Table 3 compares the PICS values in the control and alcoholic groups. The mean PICS value of the control group was $8.3 \%$ compared to the alcoholic group which was $11.3 \%$ and the alcoholic/Wernicke's encephalopathy group which was $14.7 \%$. Even though the standard deviation of each of the groups was high, the difference between the PICS values of the controls and the alcoholic groups was statistically significant as shown by the $p$ values in table 3 . There was no relationship between PICS values and the time interval between death and necropsy. Linear regression analysis showed a slope of $0 \cdot 28$. Excluding cases with epilepsy (see table 2) did not alter the results.

Each brain was assessed subjectively for macroscopic cortical atrophy, ventricular dilatation and 
cerebellar vermal atrophy.

It can be seen (table 2) that there is some correlation between the PICS values and the subjectively assessed cerebral cortical atrophy and ventricular dilatation. Assuming the upper limit of normal for PICS values to be $14.9 \%$ (mean plus two standard deviations), eight $(32 \%)$ of the 25 alcoholic cases had PICS values above this limit. Of these eight cases, five had cortical atrophy and six had ventricular dilatation. Of the remaining 18 cases only three cases were considered to have cortical atrophy and ventricular dilatation. Cerebellar vermal atrophy was noted in $36 \%$ of the alcoholic cases.

Liver disease was present in $40 \%$ of the 25 alcoholic cases (table 3 ). There were only two cases with cirrhosis, the remaining eight having fatty livers. The incidence of liver disease was higher in the alcoholic/Wernicke's encephalopathy group. Only one case (case 117) had histological evidence of hepatic encephalopathy. The mean PICS value for the alcoholic patients with liver disease was $16 \cdot 2 \%$ compared to a mean PICS of $10.3 \%$ for those alcoholics with normal livers.

\section{Discussion}

The results of this study provide objective pathological evidence that a significant proportion of chronic alcoholic patients have brain atrophy. The atrophy was reflected by an increase in the volume of the pericerebral space (PICS). PICS values were higher in those alcoholics who had superimposed Wernicke's encephalopathy caused by thiamine deficiency, and were highest in those with alcoholic liver disease (fatty liver or cirrhosis). The increase in PICS values corresponds to a mean loss of brain tissue of $41 \mathrm{~g}$ in the alcoholic group, $89 \mathrm{~g}$ in the alcoholic/Wernicke's encephalopathy group and 109 $\mathrm{g}$ in the alcoholic/liver disease group. Similar results were found in our alcoholic brain weight study in that the male alcoholic group who all had cirrhosis had a mean brain weight of $75 \mathrm{~g}$ less than controls whereas that of the alcoholic/Wernicke's encephalopathy group was $65 \mathrm{~g}$ less. ${ }^{14}$ Torvik and his colleagues 15 documented a mean brain weight difference of $31 \mathrm{~g}$ in comparing 545 male alcoholics with 586 controls.

It is important to note that there is a wide scatter of PICS values in the alcoholic groups and in fact only $32 \%$ of the cases had a PICS value higher than the normal range (mean plus two standard deviations $=14.9 \%$ ). Thus the very high incidence (up to $100 \%$ ) of cerebral shrinkage in alcoholics as demonstrated in several CT scan studies are not reflected in this pathological study. ${ }^{522}$

The accuracy and hence usefulness of the subjec- tive evaluation of macroscopic cerebral cortical atrophy and ventricular dilatation can be readily assessed from this study. There does appear to be a reasonable correlation between the subjective assessment of cortical atrophy and ventricular dilatation and high PICS values (table 2). However, the measurement of the PICS is obviously a far more accurate way of identifying loss of brain tissue. The incidence of cortical atrophy in this study (32\%) compares with previous studies of alcoholics with Wernicke's encephalopathy in which atrophy was noted in $27 \%^{12}$ and $21 \%^{13}$ of cases. Cerebellar vermal atrophy was present in $36 \%$ of the alcoholic cases. This is also consistent with other studies in that vermal atrophy was noted in $34 \%$ of 131 cases of Wernicke's encephalopathy. ${ }^{13}$ The cerebellum is normally about $10 \%$ of the brain volume. Thus loss of cerebellar tissue, as in vermal atrophy, would be unlikely to cause a significant increase in the PICS value.

Table 4 summarises previous intracranial volume studies and derived PICS values in control groups. ${ }^{171823-27}$ Techniques have varied from filling the base of the skull and skull cap with water ${ }^{23}$ sand or even ball bearings to the inflation of a balloon with water inside the cranial vault. ${ }^{27}$ The ranges of normal values are generally similar to ours. Davis and Wright ${ }^{17}$ showed a gradual increase in PICS with age. This was also evident in our control data, the increase being about $0.1 \%$ per annum after the age of 25 years. This, however, does not enter into the comparative statistical evaluations in this study as the mean age of the controls was the same or higher than that of the alcoholic groups (table 1).

An important question to consider in any necropsy study is the possible changes which might have occurred between the time of death and time at which the necropsy is done. Appel and Appel ${ }^{28}$ and Sarwar and McCormick ${ }^{29}$ claim that the brain increases in size after death, possibly due to the absorption of CSF. Hubbard and Anderson ${ }^{27}$ found that there is an estimated $5.9 \%$ decrease in ventricu-

Table 4 Literature review-PICS* values in controls

\begin{tabular}{|c|c|}
\hline Author & PICS $^{*}$ \\
\hline $\begin{array}{l}\text { Reichart, M }(1905)^{23} \\
\text { Panofsky, W and Staemmler, M }(1922)^{24} \\
\text { Alexander, L and Looney, JM }(1938)^{18} \\
\text { Hoff, H and Seitelberger, F }(1957)^{25} \\
\text { Bondareff, W }(1959)^{26} \\
\text { Davis, PJM and Wright, EA }(1917)^{17} \\
\text { Hubbard, BM and Anderson, JM } \\
\text { (1981) } \\
\text { Harper, CG and Kril, J (1984) } \\
\text { (this paper) }\end{array}$ & $\begin{array}{l}9-20 \% \\
5 \cdot 8-13 \cdot 2 \% \\
4-9 \% \\
5-21 \% \\
9-11 \% \\
7 \cdot 8 \pm 1.6 \% \text { (SEM) } \\
11 \cdot 7 \pm 4 \cdot 1 \% \text { (SD) } \\
8 \cdot 3 \pm 3.3 \% \text { (SD) }\end{array}$ \\
\hline
\end{tabular}

${ }^{*}$ PICS = Pericerebral space derived from brain volume and intracranial volume 
Table 5 Potential causes of cerebral atrophy in chronic alcoholics-liver disease or vitamin deficiency state?

\begin{tabular}{lllc}
\hline Group & \multirow{2}{*}{$\begin{array}{l}\text { Number } \\
\text { of cases }\end{array}$} & \multicolumn{2}{c}{ Macroscopic brain changes } \\
\cline { 3 - 4 } & & Cerebral atrophy & Ventricular dilatation \\
\hline Cirrhosis & 48 & $8 \%$ & $0 \%$ \\
Wernicke's encephalopathy & 53 & $26 \%$ & $34 \%$ \\
Wernicke's encephalopathy & 49 & $16 \%$ & $33 \%$ \\
\hline Cirrhosis & $49 \%$ & & \\
\hline
\end{tabular}

lar volume after death due to the shift of CSF into brain tissue. This observation was made by comparing CT scans and ventricular volume measurements after fixation of the brain. Davis and Wright ${ }^{17}$ examined the question of changes in PICS values in relation to the time delay between death and necropsy. They showed that the brain volume did not change significantly up to five days after death. Our results showed a similar lack of correlation. In fact, the mean time delay was 22 hours in the control group compared to 43 hours for the alcoholic groups. According to the authors cited above ${ }^{28} 29$ this should have caused a greater reduction in the PICS value of the alcoholic group than the control group. Hubard and Anderson ${ }^{27}$ used the balloon technique $^{17}$ to determine PICS values in 20 cases of Alzheimer's disease. However, to our knowledge there has been no previous study of PICS values in a group of alcoholic patients. Alexander and Looney ${ }^{18}$ included two chronic alcoholic patients in their study. The PICS values of those cases were $12 \cdot 1 \%$ and $15 \cdot 1 \%$, both well above their stated normal range of $4-9 \%$.

Of some interest is the fact that alcoholics with liver disease (fatty liver or cirrhosis) had higher PICS values $(16.2 \%)$ than those with normal liver histology $(10 \cdot 3 \%)$. This finding was unrelated to hepatic encephalopathy which was noted in only one case. It has been previously suggested that cerebral atrophy and associated ventricular enlargement in alcoholics could be related to liver disease..$^{30}$ Acker et al $^{31}$ recently addressed the same question and carried out liver biopsies, CT scans and psychometric tests on 41 alcoholic patients. They showed that the degree of liver damage correlated significantly with both sulcal and Sylvian fissure widening. This is contrary to the results of Lee and her colleagues ${ }^{32}$ who carried out a similar study in a group of 37 young alcoholics. They concluded that there was no significant correlation between liver disease and cortical atrophy, although four of their seven cases with cirrhosis had cortical atrophy. They added that a larger study was necessary to confirm their data. Acker $e a^{31}$ suggested that it would be interesting to study the brains of patients with non-alcoholic liver disease. Of the 115 cases in our original study, there were two cases with cardiac cirrhosis. Their respective PICS values were $15.4 \%$ and $23.9 \%$, both well above normal, but obviously no conclusions can be drawn from these isolated cases.

In a separate study of the brains of 150 chronic alcoholic patients (unpublished data), a subjective assessment of cerebral atrophy and ventricular dilatation was made. Three groups of alcoholics were identified according to whether they had cirrhosis alone, Wernicke's encephalopathy alone or cirrhosis plus Wernicke's encephalopathy. As shown in table 5 those alcoholics with cirrhosis alone had a much lower incidence of cerebral atrophy and ventricular dilatation than the other two groups. In addition, there was no increase in the incidence of cerebral atrophy in patients with Wernicke's encephalopathy when cirrhosis was also present. These findings suggest that the nutritional deficiency state which causes Wernicke's encephalopathy (thiamine deficiency) plays the major role in the causation of cerebral cortical atrophy in chronic alcoholics. This is contrary to the results of this study in which PICS values tend to be highest in those alcoholics with liver disease.

In summary, as the result of the development of a relatively simple technique for measuring the ICV at necropsy by making a polyurethane foam cast, we have been able to derive some accurate quantitative data concerning loss of brain tissue in chronic alcoholic patients compared to a control group. The loss of brain tissue is significant and likely to be more severe if the patient has Wernicke's encephalopathy (thiamine deficiency) and in those patients with alcoholic liver disease even when there is no histological evidence of hepatic encephalopathy. However, further studies will be necessary regarding the complicated inter-relationships between cerebral atrophy and the potential pathogenetic factors which include alcohol, nutritional vitamin deficiences and liver disease.

The material used in this neuropathological study will be used for further quantitative morphometric analyses to determine which areas of the cerebral hemispheres are reduced in volume in chronic alcoholic patients.

We have had much assistance and cooperation in this study. In particular we are grateful to the staff of 
the Forensic Department of the Perth City Coroner's Department for their continued patient assistance. Mr Livio Mina and Dr Barry Page helped in the filing of our data and statistical analyses. Mrs Patsy Cunningham typed the manuscript. Technical assistance on the use of the polyurethane foam was provided by ICI Australia Operations Pty Ltd.

This research was supported by grants from the Royal Perth Hospital Research Foundation, the Australian Brain Foundation and the Australian Associated Brewers. Mr Rick Timm assisted with art work and photography.

\section{References}

' Brewer B, Perrett L. Brain damage due to alcohol consumption: an air-encephalographic, psychometric and electro-encephalographic study. $\mathrm{Br} J$ Addict 1971;66: 170-82.

${ }^{2}$ Wilkinson DA, Carlen PL. Relationship of neuropsychological test performance to brain morphology in amnesic and non-amnesic chronic alcoholics. Acta Psychiatr Scand 1980;62(suppl 286):89-102.

${ }^{3}$ Bergman H, Borg S, Hindmarsh T, Ideström C-M, Mützell $S$. Computed tomography of the brain and neuropsychological assessment of male alcoholic patients and a random sample from the general male population. Acta Psychiatr Scand 1980;62(suppl 286):47-56.

${ }^{4}$ Ron MA. The alcoholic brain: CT scan and psychological findings. Psych Med 1983 (monograph suppl 3): 1-33.

${ }^{5}$ Carlen PL, Wortzman G, Holgate RC, Wilkinson DA, Rankin JG. Reversible cerebral atrophy in recently abstinent chronic alcoholics measured by computed tomographic scans. Science 1978;200:1076-8.

- Artman H. Reversible enlargement of cerebral spinal fluid spaces in alcoholics. Ann $J$ Neuroradiol 1981;2:23-7.

7 Tarter RE. An analysis of cognitive deficits in chronic alcoholics. J Nerv Ment Dis 1973;157:138-47.

${ }^{8}$ Lishman WA. Cerebral disorder in alcoholism: syndromes of impairment. Brain 1981;104:1-20.

9 Anonymous. Alcoholic Brain Damage [Editorial]. Lancet $1981 ; \mathrm{i}: 477-8$.

10 Thompson AD, Ron MA. Alcohol-related brain damage. Br Med Bull 1982;38:87-91.

$"$ Courville CB. Effects of Alcohol in the Nervous System of Man. Los Angeles: San Lucas Press, 1955.

12 Victor M, Adams RD, Collins GH. The WernickeKorsakoff Syndrome. Contemporary Neurology Series. Oxford: Blackwell, 1971.

${ }^{13}$ Harper C. The incidence of Wernicke's encephalopathy in Australia-a neuropathological study of 131 cases. J Neurol Neurosurg Psychiatry 1983;46:593-8.

${ }^{14}$ Harper CG, Blumbergs PC. Brain weights in alcoholics.
J Neurol Neurosurg Psychiatry 1982;45:838-40.

15 Torvik A, Lindboe CF, Rodge S. Brain lesions in alcoholics. A neuropathological study with clinical correlations. J Neurol Sci 1982;56:233-48.

${ }^{16}$ Dekaban AS, Sadowsky D. Changes in brain weights during the span of human life: relation of brain weights to body heights and body weights. Ann Neurol 1978;4:345-56.

${ }^{17}$ Davis PJM, Wright EA. A new method for measuring cranial cavity volume and its application to the assessmeñt of cerebral atrophy at autopsy. Neuropathol Appl Neurobiol 1977;3:341-58.

${ }^{18}$ Alexander L, Looney JM. Physiochemical properties of brain, especially in senile dementia and cerebral oedema. Arch Neurol Psychiatry 1938;40:877-902.

${ }^{19}$ Harper C, Kril J, Raven D, Jones N. Intracranial cavity volumes: a new method and its potential application. Neuropathol App Neurobiol 1984;10:25-32.

${ }^{20}$ Wilkinson P, Kornaczewski A, Rankin JG, Santamaria JN. Physical disease in alcoholism. Initial survey of 100 patients. Med J Aust 1971;1:1217-23.

${ }^{21}$ Snedecor GW. Statistical Methods: Applied to Experiments in Agriculture and Biology. 5th ed. Iowa: Iowa State University Press, 1964;96-100.

${ }^{22}$ Cala LA, Mastaglia FL. Computerized axial tomography in the detection of brain damage. Med $J$ Aust 1980; 2: 193-8.

${ }^{23}$ Reichardt M. Über die Bestimmung der Schädelkapazität an der Leiche. Allgemeine Zeitschrift für Psychiatrie 1905; 62:787-801.

${ }^{24}$ Panofsky W, Staemmler M. Untersuchungen über Hirngewicht und Schädelkapazität nach der Reichardtschen Methode. Frankfurter Zeitschrift fur Pathologie 1922;26:519-49.

${ }^{25}$ Hoff $\mathrm{H}$, Sietelberger F. Die Altersveränderungen des menschlichen Gehirns. Ztschr Alternsforsch 1957; 10:307-18.

${ }^{26}$ Bondareff $\mathrm{W}$. Morphology of the aging nervous system: In: Birren JE, ed. Handbook of Aging and the Individual. Chicago: University of Chicago Press, 1959:136-72.

${ }^{27}$ Hubbard BM, Anderson JM. Age, senile dementia and ventricular enlargement. J Neurol Neurosurg Psychiatry 1981;44:631-5.

${ }^{28}$ Appel FW, Appel EM. Intracranial variation in the weight of the human brain (concluded). Hum Biol $1942 ; 14: 235-50$.

${ }^{29}$ Sarwar M, McCormick WF. Decrease in ventricular and sulcal size after death. Radiology 1978;127:409-11.

${ }^{30}$ Fox JH, Ramsey RG, Huckman MS, Proske AE. Cerebral ventricular enlargement. Chronic alcoholics examined by computerized tomography. JAMA 1970;263:365-8.

31 Acker W, Aps EJ, Majumdar SK, Shaw GK, Thomson AD. The relationship between brain and liver damage in chronic alcoholic patients. J Neurol Neurosurg Psychiatry 1982;45:984-7.

${ }^{32}$ Lee L, Hard F, Møller L, Haubeck A, Jensen E. Alcohol-induced brain damage and liver damage in young males. Lancet 1979;2:759-61. 